\title{
Cure characteristics of nanocomposites containing imidazolium ionic liquid modified carbon nanotubes and styrene butadiene rubber
}

\begin{abstract}
Herein, imdazolium type ionic liquid modified Multiwalled carbon nanotube based styrene butadiene rubber nanocomposites is prepared by simple two roll ill mixing. Ionic liquid facilitates the dispersion of MWCNT in polymer matrix which is evident from Transmission electron microscopy images. The effect of the incorporation of a modified MWCNT (f- MWCNT) on the vulcanization kinetics of natural rubber was investigated by means of cure-meter testing (Figure 1).
\end{abstract}

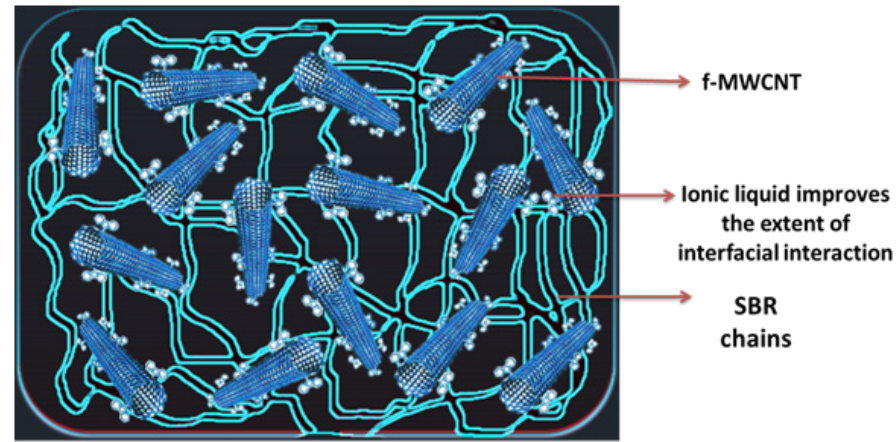

Figure I Vulcanization kinetics of natural rubber was investigated by means of cure-meter testing.
Volume 2 Issue 6 - 2018

\author{
Jiji Abraham, ' Ajesh K Zacharia, ${ }^{2}$ Soney C \\ George, ${ }^{3}$ Sabu Thomas' \\ 'International and Inter University Centre for Nanoscience and \\ Nanotechnology, Mahatma Gandhi University, India \\ 2Marthoma College Thiruvalla, India \\ ${ }^{3}$ Amal Jyothi College of Engineering, India
}

\begin{abstract}
Correspondence: Sabu Thomas, International and Inter University Centre for Nanoscience and Nanotechnology, Mahatma Gandhi University, P.D. Hills, Kottayam, Kerala, 686560, India,Email sabuthamas@mgu.ac.in
\end{abstract}

Received: October 08, 2018 | Published: December 05, 2018

\section{Introduction}

Potential applications as well as strength and durability of polymers can be enriched by the reinforcement using various nanosized fillers. Fillers with very high aspect ratio and different dimensionality or morphology can be served as ideal reinforcing agent in the viewpoint of their enhanced properties at low nanofiller loading thereby weight savings of final material. Among the various nanofillers, carbon nanotubes can be pursued as a promising reinforcing agent due to their superb physical properties especially mechanical characteristics with tensile strength of $60 \mathrm{GPa}$ and Young's modulus of 1TPa. Appropriate dispersion MWCNT because interactions between neighbouring tubes and the lack of efficient load transfer between MWCNT and polymer matrix due to the atomically smooth surface of MWCNT are the two critical difficulties in composite processing. Incorporation of active groups on MWCNT by emerging chemistry is a good method to overcome these tasks. The effective load transfer can be occurred by primary or secondary bonding between filler and polymer or entanglement with polymer. By functionalization, fillers became the part of the cross-linked structure rather than separate segments. Use of ionic liquid as novel dispersant for MWCNT has been developed as an environment friendly technology to functionalize MWCNTs. Commonly reported dispersants are solid in state which needs additional solvent to disperse MWCNT. In contrast ionic liquids are fluid at room temperature and are made entirely of ions. Special features of ionic liquid like high boiling point, low toxicity, high ionic conductivity and good solvation properties made them an attractive candidate in green chemistry. Based on this, several works have been reported on the surface functionalization of MWCNT by ionic liquid and their use as a reinforcing agent in elastomers. The property improvements and the reinforcement mechanism by the addition of surface modified MWCNT are influenced by the behaviour of interfacial region and microstructural development in the composites. Positive correlation between mechanical performance and vulcanisation characteristics of rubber composites were already established by various researchers. Formation of three dimensional network structures via sulphur linkages upon vulcanisation leads to variations in physical and mechanical characteristics of elastomers to great extent. Therefore, investigation of both the cure reaction and its kinetics provide detailed information regarding vulcanisation mechanism and the correlation between cure and mechanical properties of vulcanised rubber. In this paper, cure kinetics is of prepared nanocomposites are studied in detail using an autocatalytic model proposed by Kamal and Ryan. Microstructural developments in nanocomposites are investigated by transmission electron microscopy images.

\section{Materials and methods}

Multiwall carbon nanotubes (NANOCYLTM NC7000) with minimum purity of $90 \%$, average diameter of ca.10nm, average length of ca. $1.5 \mu \mathrm{m}$ were used in this work. Styrene butadiene Rubber (Synaprene 1502) was used as the matrix. Surface modification of MWCNT was done using ionic liquid, 1-benzyl-3-methylimidazolium chloride purchased from Reinste Nano ventures. All other compounding ingredients are purchased from Merck Chemicals, Mumbai. Nanocomposite fabrication was done in three steps: Phase 
I: Surface functionalization of MWCNT using ionic liquid, Phase II: Nanocomposite preparation by Two roll mill mixing, Phase III: Compression molding. Schematic diagram showing different steps in

Table I Different f-MWCNT/SBR nanocomposites prepared for this work

*I phr ionic liquid= I mmol of ionic liquid the fabrication of nanocomposites are displayed in (Figure 2) (Table 1) shows samples prepared for this study.

\begin{tabular}{llll}
\hline Sample designation & MWCNT(phr) & lonic liquid $(\mathbf{p h r})$ & Ratio between MWCNT and lonic liquid \\
\hline TOILO & 0 & 0 & $0: 00$ \\
TIILI & 1 & 1 & $1: 01$ \\
TIILI & 3 & 3 & $1: 01$ \\
T5ILI & 5 & 5 & $1: 01$ \\
T7ILI & 7 & 7 & $1: 01$ \\
TIOILI & 10 & 10 & $1: 01$ \\
\hline
\end{tabular}
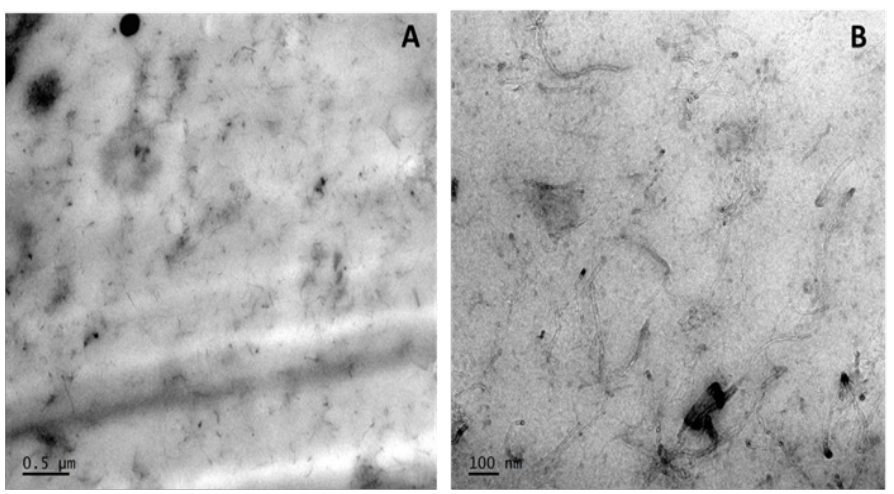

Figure 2 Transmission electron microscopy images of T5ILI in different magnifications

\section{Characterization techniques}

The cure characteristics of the SBR composites were determined with a Moving die rheometer (MDR 3000, MonTech, Germany) at $160^{\circ} \mathrm{C}$ for $30 \mathrm{~min}$. The vulcanization behaviour of neat SBR and SBR composites were determined at $140^{\circ} \mathrm{C}, 160^{\circ} \mathrm{C}$ and $180^{\circ} \mathrm{C}$. The cure reaction rate constant was calculated from the vulcanization reaction and then the vulcanization kinetics was also analysed. The morphology of the composites was analysed by TEM (JEM-2100HRTEM). The cryocut specimens prepared using an ultra-microtome (Leica, Ultra cut UCT) were placed on 300 mesh $\mathrm{Cu}$ grids $(35 \mathrm{~mm}$ diameter) and were analysed.

\section{Results and discussion}

\section{Microstructural studies, transmission electron microscopy (TEM)}

TEM technique was carried out to know the dispersion situation of the modified MWCNTs in polymer matrix, as displayed in Figure 2. Modified MWCTs were relatively finely distributed in matrix indicating the good interfacial communication between matrix and filler.

\section{Cure characteristics and theoretical modelling}

To elucidate the influence of f-MWCNT concentration on the vulcanisation kinetics of SBR, cure graphs of nanocomposites are presented in Figure 3A. Systematic shifting of curing curves towards the short time side with increasing f-MWCNT is evident from this figure, proposing that the vulcanisation phenomenon of SBR is augmented. It is found that ionic liquids can be used to enhance the speed of the sulphur vulcanisation of butadiene-styrene elastomer composites. Here imidazolium group of ionic liquid present on the surface of MWCNT can act as cure accelerator. As seen in Figure 3B both scorch time and cure time drop rapidly with increase in filler loading up to $3 \mathrm{phr}$ f-MWCNT, and then levels off t90-ts 2 , which is a measure of vulcanisation time and rate reduced with increase in filler loading.
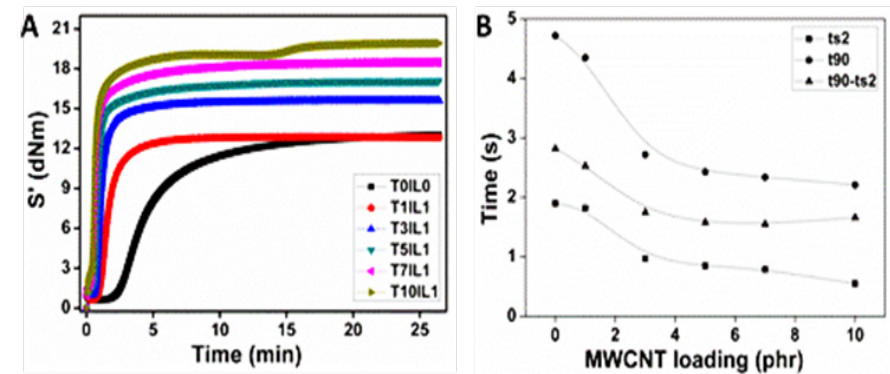

Figure 3 (A) Cure graphs of nanocomposites having diverse f-MWCNT loading, (B) Variation in scorch time and cure time with f-MWCNT loading.

\section{Vulcanisation kinetics}

To have a better understanding of the influence of f-MWCNT on the vulcanisation process of SBR nanocomposites, the kinetics of vulcanisation is studied based on cure rheometric data. Vulcanisation kinetics of rubber can be modelled using a differential equation related to time and temperature. Kamal and Ryan in their model proposed that the overall reactions during vulcanisation process could contain autocatalytic reactions. Equation is given as follows,

$$
\frac{d \alpha}{d t}=K(T) f \alpha(1)
$$

Where $\alpha$ is the degree of vulcanisation, $\mathrm{d} \alpha / \mathrm{dt}$ is the vulcanisation rate, $t$ is the time, $K$ is a kinetic constant at temperature $T$, and $f(\alpha)$ is a function corresponding to the phenomenological model. The degree of vulcanisation $\alpha$ calculated from torque time curves obtained by Moving die rheometer (MDR) is as follows

$$
\alpha=\frac{\mathrm{M}_{\mathrm{t}}-\mathrm{M}_{0}}{\mathrm{M}_{\infty}-\mathrm{M}_{0}}(2)
$$

Where M0, Mt, and $\mathrm{M}$ are the torque values at time zero, at a given curing time and at the end of the vulcanisation process respectively. It has been generally realized that the vulcanisation process is an autocatalytic reaction, thus $f(\alpha)$ is given as 


$$
f(\alpha)=\alpha^{m}(1-\alpha)^{n}
$$

Where $0<\mathrm{m}<1$ and $\mathrm{n}>1$ are both the orders of reaction. Thus, Eq. (4.1) can be given as:

$$
\frac{d \alpha}{d t}=K(T) \alpha^{m}(1-\alpha)^{n}(4)
$$

As shown in Figure 4 the experimental data can be well fitted with equation 4 . The reasonable good closeness between experimental and theoretical prediction and also the fraction values of $\mathrm{n}$ and $\mathrm{m}$ suggest that the vulcanisation process cannot be characterized by a simple elemental reaction, but rather by various reactions which can occur simultaneously or in series, and these reactions undergo an autocatalytic process during vulcanisation. From the fitting parameters displayed in Table 2, it is clear that the vulcanisation rate is promoted with f-MWCNT loading. Here k value increases with filler loading which suggests the improvement of vulcanisation rate with filler loading. Dependency of the vulcanisation reaction on the initial reactants of the compound is evident from the large $n$ value as compared to $m$ value.

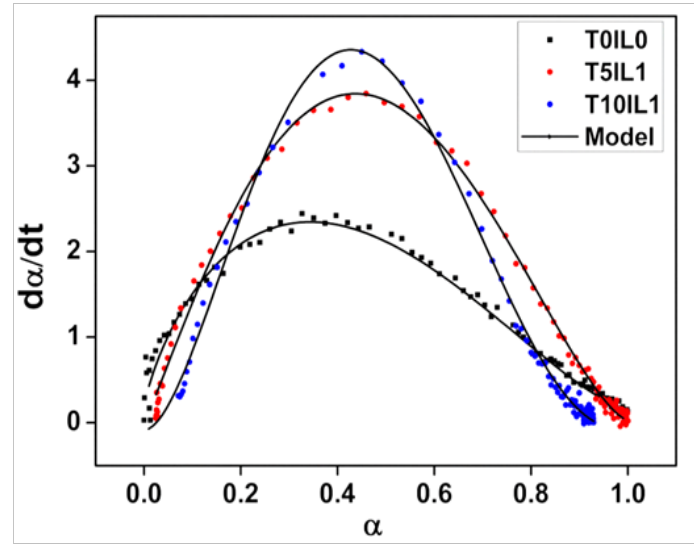

Figure 4 Plots of vulcanisation rate against degree of vulcanisation for the nanocomposites at $160^{\circ} \mathrm{C}$. The lines are the results predicted from Equation. 4

Table 2 Kinetic parameters obtained by fitting the experimental data in Figure

\begin{tabular}{|c|c|c|c|c|c|}
\hline Sample & Temperature (K) & $k\left(\min ^{-1}\right)$ & $\mathbf{m}$ & $\mathbf{n}$ & $m+n$ \\
\hline \multirow{3}{*}{ TOILO } & 413 & 0.045 & 0.64 & 0.98 & 1.62 \\
\hline & 423 & 0.067 & 0.72 & 1.32 & 2.04 \\
\hline & 443 & 0.153 & 0.76 & 1.46 & 2.22 \\
\hline \multirow{3}{*}{ T5ILI } & 413 & 0.401 & 0.68 & 1.51 & 2.19 \\
\hline & 423 & 0.608 & 0.79 & 2.23 & 3.02 \\
\hline & 443 & 0.881 & 0.81 & 2.63 & 3.44 \\
\hline \multirow{3}{*}{ TIOILI } & 413 & 1.43 & 0.73 & 2.78 & 3.51 \\
\hline & 423 & 2.36 & 0.87 & 2.89 & 3.76 \\
\hline & 443 & 3.91 & 0.98 & 3.07 & 4.05 \\
\hline
\end{tabular}
2 with Equation 4

\section{Conclusion}

f-MWCNT/SBR nanocomposites were prepared by two roll mill mixing method. TEM results suggest that the method is efficient in dispersing MWCNT in the SBR matrix. It is found that ionic liquids can be used as accelerators for the sulphur vulcanisation of SBR composites. The increase in torque with filler loading can be attributed to the formation of three dimensional network of MWCNT in rubber matrix. Vulcanisation kinetics study shows that cure reaction is an autocatalytic reaction. ${ }^{1-13}$

\section{Acknowledgments}

None.

\section{Conflicts of interest}

The Authors have no conflicts of interest.

\section{References}

1. Abraham J, Maria HJ, George SC, et al. Transport characteristics of organic solvents through carbon nanotube filled styrene butadiene rubber nanocomposites: the influence of rubber-filler interaction, the degree of reinforcement and morphology. Physical Chemistry Chemical Physics. 2015;17(17):11217-11228

2. Coleman JN, Khan U, Blau WJ, et al. Small but strong: a review of the mechanical properties of carbon nanotube-polymer composites. Carbon. 2006;44(9):1624-1652

3. Marsh KN, Boxall JA, Lichtenthaler R. Room temperature ionic liquids and their mixtures a review. Fluid Phase Equilibria. 2004;219(1):93-98.

4. Welton T. Ionic liquids in green chemistry. Green Chemistry. 2011;13(2):225.

5. Abraham J, Kailas L, Kalarikkal N, et al. Developing highly conducting and mechanically durable styrene butadiene rubber composites with tailored microstructural properties by a green approach using ionic liquid modified MWCNTs. RSC Advances. 2016;6(39):32493-32504

6. Ma H, Chu B, Hsiao BS. Modification of carbon nanotubes with fluorinated ionic liquid for improving processability of fluoro-ethylenepropylene. European Polymer Journal. 2017;87:398-405.

7. Abraham J, Thomas J, Kalarikkal N, et al. Static and Dynamic Mechanical Characteristics of Ionic Liquid Modified MWCNT-SBR Composites: Theoretical Perspectives for the Nanoscale Reinforcement Mechanism. The Journal of Physical Chemistry B. 2018;122(4):1525-1536.

8. Zhong B, Jia Z, Hu D, et al. Enhancing interfacial interaction and mechanical properties of styrene-butadiene rubber composites via silica-supported vulcanization accelerator. Composites Part A: Applied Science and Manufacturing. 2017;96:129-136.

9. Zhong B, Jia Z, Hu D, et al. Surface modification of halloysite nanotubes by vulcanization accelerator and properties of styrene-butadiene rubber nanocomposites with modified halloysite nanotubes. Applied Surface Science. 2016;366:193-201

10. Maciejewska M, Walkiewicz F, Zaborski M. Novel ionic liquids as accelerators for the sulfur vulcanization of butadiene-styrene elastomer composites. Industrial \& Engineering Chemistry Research. 2013;52(25):8410-8415.

11. Laskowska A, Marzec A, Boiteux G, et al. Effect of imidazolium ionic liquid type on the properties of nitrile rubber composites. Polymer International. 2013;62(11):1575-1582.

12. Kamal MR, Ryan ME. The behavior of thermosetting compounds in injection molding cavities. Polymer Engineering \& Science. 1980;20(13):859-867.

13. Wu J, Xing W, Huang G, et al. Vulcanization kinetics of graphene/ natural rubber nanocomposites. Polymer. 2013;54(13):3314-3323. 